\title{
Idiopatisk intrakranial hypertensjon
}

\author{
Ved idiopatisk intrakranial hypertensjon er det økt intrakranialt trykk \\ uten romoppfyllende sykdomsprosesser, sinusvenetrombose eller affi- \\ serte hjernehinner. Tilstanden er forbundet med overvekt, spesielt hos \\ kvinner i fertil alder. Idiopatisk intrakranial hypertensjon er en sjelden, \\ men alvorlig årsak til hodepine og en differensialdiagnosene ved nyopp- \\ stått hodepine, spesielt dersom pasienten har ikke-migrenøse synsfor- \\ styrrelser og rapporterer om pulsatil tinnitus, hjernenervepareser eller \\ radikulopati.
}

Idiopatisk intrakranial hypertensjon er en tilstand med økt intrakranialt trykk i fravær av romoppfyllende sykdomsprosess, sinusvenetrombose og affiserte hjernehinner (1). Prevalensen er $1-2$ per 100000 , men hos overvektige kvinner i fertil alder er den opp mot 21 per 100000 (2). Med økende overvekt i befolkningen kan det forventes tilsvarende økende prevalens av tilstanden. Dog kan den også forekomme hos slanke personer og hos barn, men er mindre hyppig $\mathrm{i}$ disse gruppene.

Hos prepubertale barn som rammes er kjønnsfordelingen lik, og mange er normalvektige (2). De bakenforliggende patofysiologiske mekanismene er fortsatt uavklart (3). Én av ti pasienter med idiopatisk intrakranial hypertensjon utvikler synsnerveatrofi med alvorlig synsreduksjon, og noen blir blinde (4). Tilstanden krever derfor årvåkenhet og raske tiltak som kan forhindre tap av synet.

Utredning og behandling krever dels bruk av invasive prosedyrer, og det er viktig å kunne identifisere dem som trenger rask behandling (dvs. innen ett til noen få døgn) og samtidig unngå overdiagnostisering og overbehandling i de tilfeller der synet ikke er truet (5). Hodepinen i seg selv er ikke indikasjon for kirurgi ved idiopatisk intrakranial hypertensjon.

Formålet med denne artikkelen er å drøfte kliniske momenter i forbindelse med diagnostisering, behandling og oppfølging av idiopatisk intrakranial hypertensjon. Artikkelen er basert på ikke-systematiske litteratursøk i PubMed og Cochrane-databasen og på forfatternes egne kliniske erfaringer med tilstanden.

\section{Diagnosekriterier}

Den amerikanske nevrokirurgen Walter Dandy publiserte i 1937 en artikkel om 22 pasienter med hodepine, synsutfall og papillødem uten påviselig årsak (6). Flere modifikasjoner av de såkalte Dandy-kriteriene er foreslått etter hvert som kunnskapen og utredningsmulighetene har økt (1).

Papillødem og forhøyet åpningstrykk av spinalvæske kombinert med normal nevrologisk status, normal spinalvæskesammensetning og ingen romoppfyllende prosesser ved cerebral bildediagnostikk (kriteriene A-E) gir grunnlag for å stille diagnosen «sikker idiopatisk intrakranial hypertensjon» (ramme 1).

Diagnosen «idiopatisk intrakranial hypertensjon uten papillødem» kan stilles ved fravær av dette dersom kriteriene B-D er til stede og det samtidig er parese av n. abducens, dog er dette kravet muligens for utelukkende (3). Pasienter med tilsynelatende normalt spinalvæsketrykk kan diagnostiseres med «sannsynlig idiopatisk intrakranial hypertensjon» hvis samtlige kriterier fra A til D er oppfylt og papillødemet er bilateralt (tab 1). Kriteriene åpner således for behandling av pasienter med truet synsfunksjon (ødematøs papill) uten påvist patologisk spinalvæsketrykk.

Friedman og medarbeidere foreslår at man kan anta, men ikke endelig stille diagnosen hvis det er minimum tre radiologiske funn uten at papillødem og n. abducensparese er til stede (1). Det understrekes at radiologiske funn som indikerer forhøyet intrakranialt trykk kan støtte diagnosen, men at dette i seg selv ikke er et tilstrekkelig funn.

\section{Kliniske karakteristika}

Pasienter rapporterer typisk om nyoppstått hodepine som vanligvis skiller seg fra tidligere hodepineplager både i karakter og intensitet. Halvparten har hodepine daglig. Smerten er vanligvis ikke stillingsrelatert, men kan forverres ved stillingsendring. Enkelte har mest hodepine om morgenen. Smerten kan være ensidig, migrenelignende, holokranial eller retrobulbær. Hodepinen er altså heterogen, og det er få «typiske» trekk $(1,6-8)$.

\author{
Anette Huuse Farmen* \\ anette.farmen@gmail.com \\ Nevrologisk avdeling \\ Oslo universitetssykehus, Rikshospitalet

\section{Geir Ringstad} \\ Nevroradiologisk enhet \\ Klinikk for radiologi og nukleærmedisin \\ Oslo universitetssykehus, Rikshospitalet

\section{Emilia Kerty} \\ Nevrologisk avdeling \\ Oslo universitetssykehus, Rikshospitalet \\ og \\ Universitetet i Oslo
}

* Nåværende adresse:

Nevrologisk avdeling

Sykehuset Innlandet Lillehammer

\section{HOVEDBUDSKAP}

Idiopatisk intrakranial hypertensjon er en sjelden, men viktig årsak til hodepine. Tilstanden forekommer hyppigst hos overvektige kvinner i fertil alder

For endelig diagnose er øyelegevurdering, bildediagnostikk og undersøkelse av spinalvæsketrykk nødvendig

De fleste blir bedre med vektreduksjon og behandling med karbonsyreanhydrasehemmer, men enkelte med truet synsfunksjon trenger rask nevrokirurgisk behandling

Symptomer, kliniske funn og behandlingsrespons bør følges opp jevnlig i et samarbeid mellom fastlege, nevrolog og øyelege 


\section{RAMME 1}

Modifiserte Dandy-kriterier fra 2013, etter Friedman og medarbeidere (1). Diagnosen idiopatisk intrakranial hypertensjon regnes som sikker dersom alle kriteriene er oppfylt

\section{A Papillødem}

B Normal nevrologisk status, unntatt hjernenerveutfall

C Romoppfyllende prosess, hydrocephalus, affiserte hjernehinner og venetrombose utelukket med bildediagnostikk

D Normal cerebrospinalvæske

E Høyt åpningstrykk ved spinalpunksjon I $\geq 250 \mathrm{~mm} \mathrm{H}_{2} \mathrm{O}$ hos voksne, $\geq 280 \mathrm{~mm} \mathrm{H}_{2} \mathrm{O}$ hos barn, $\geq 250 \mathrm{~mm} \mathrm{H}_{2} \mathrm{O}$ hvis barnet ikke er i narkose og ikke er overvektig)

Objektive synsforandringer hos pasienter med mulig eller sikker idiopatisk intrakranial hypertensjon krever rask utredning og behandling. Synsfeltet påvirkes oftest før synsskarpheten. 10-30\% har redusert visus ved diagnosetidspunktet. Opptil $25 \%$ kan få alvorlig synstap dersom behandlingen startes for sent, og enkelte utvikler bilateral blindhet $(4,7)$. Fulminant forløp med betydelig synstap og papillødem i løpet av få uker fra symptomstart er sjeldent, men krever rask diagnose og behandling, og kirurgisk intervensjon innen få døgn kan være indisert (fig 1).

Rundt $70 \%$ av pasientene rapporterer om kortvarige synsbortfall på ett øye, som kan ligne på amaurosis fugax. I tillegg rapporteres fotopsi og lysglimt av sekunders varighet, som kan komme spontant eller utløses av stillingsendring, sterkt lys eller Valsalvamanøver. Årsaken er sannsynligvis forbigående iskemi i den fremre del av n. opticus eller papillen, forårsaket av papillødem (4). Andre klassiske symptomer er pulsatil tinnitus og smerter i nakke og rygg, eventuelt kvalme og oppkast. Isolert hjernenerveaffeksjon kan forekomme (2, 7-9). Påvirket reaksjonstid og prosesseringshastighet er rapportert, men graden av kognitiv reduksjon er usikker (10).

\section{Utredning}

Nøyaktig anamnese vedrørende hodepine og synsutfall, medikamentbruk og vektøkning er essensielt. Generell somatisk og nevrologisk status, blodtrykksmåling, orienterende synsfelts- og visusundersøkelse samt oftalmoskopi er nødvendig. Ved anamnestisk økende tåkesyn, synsfeltspåvirkning eller mistanke om papillødem ved oftalmoskopi bør øyelege kontaktes samme dag for rask videre undersøkelse.

Øyelegen tester synsfeltet objektivt ved autoperimetri og vurderer papillødem. Et tidlig og hyppig perimetrifunn er forstørret blind flekk og inferonasalt synsfelstutfall. Senere kan bueformede (arkuate) synsfeltsdefekter og nedsatt sensitivitet for hele synsfeltet registreres. Selve synsskarpheten kan være normal langt ut i forløpet og er ikke egnet til å monitorere tilstanden, det er heller ikke fargesynsundersøkelse og visuelt utløste potensialer (VEP) (7).

Papillødem kan vurderes etter ulike skalaer (11), men graderingen har høy interobservatørvariabilitet, og fundusfoto bør gjøres ved hver øyelegekontroll. Fundusfoto kan enkelt utføres uten mydriasis (utvidelse av pupillen) og sikrer objektivitet og kontinuitet i vurderingen. Papillødem kan være asymmetrisk eller mangle, særlig ved tilbakefall etter gjennomgått idiopatisk intrakranial hypertensjon eller tidligere skade på synsnerven.

\section{Spinalpunksjon}

Spinalpunksjon med trykkmåling og undersøkelse av cerebrospinalvæsken må gjøres for endelig diagnose. Mange opplever bedring av både hodepine og synsplager etter tapping av spinalvæske. Respons på spinalvæsketapping er alene ikke diagnostisk og for subjektiv til å gi sikker støtte til diagnosen (1). Pasienter med idiopatisk intrakranial hypertensjon kan også oppleve postpunksjonshodepine.

Trykket i cerebrospinalvæsken måles med pasienten i sideleie og mest mulig utstrakte ben. Sedasjon og Valsalva-manøver (f.eks. hvis pasienten holder pusten) kan gi falskt forhøyet åpningstrykk. Et åpningstrykk $\geq 250 \mathrm{~mm} \mathrm{H}_{2} \mathrm{O}$ hos voksne regnes som patologisk. Barn spinalpunkteres som regel i narkose. Siden narkose kan gi hyperkapni, som øker spinalvæsketrykket, er grensen for patologisk spinalvæsketrykk hos barn satt til $\geq 280 \mathrm{~mm} \mathrm{H}_{2} \mathrm{O}$ (12).

Trykket i spinalvæskesystemet er dynamisk og varierer. Et lavere åpningstrykk enn forventet kan skyldes at man tidsmessig har truffet nadir, bunnen av en trykkbølge, og bør ikke være til hinder for diagnosen hos en pasient der kliniske funn og funn ellers passer med kriteriene og det er sikkert papillødem (jf. diagnosekriteriene).

I en studie fra Rikshospitalet hadde kun syv av 14 pasienter med idiopatisk intrakranial hypertensjon et gjennomsnittlig spinalvæsketrykk på $>15 \mathrm{~cm} \mathrm{H}_{2} \mathrm{O}$ målt ved kontinuerlig trykkmåling (13). Tilsvarende skal et isolert høyt åpningstrykk ikke være avgjørende for diagnosen hos en pasient som ellers ikke har funn eller symptomer passende med idiopatisk intrakranial hypertensjon (1). Der det er tvil om diagnosen eller uventet trykk, bør spinalpunksjon med trykkmåling gjentas. I enkelte spesielle tilfeller gjøres døgnregistrering av intrakranialt trykk for å diagnostisere patologisk trykkpulsatilitet (13), men dette er ikke en vanlig del av utredningen.

\section{Bildediagnostikk}

Hensikten med radiologisk undersøkelse er primært å utelukke bakenforliggende årsak til symptomene, men i fravær av papillødem og abducensparese kan radiologiske funn indikere høyt intrakranialt trykk. Det er imidlertid viktig å unngå overdiagnostisering på bakgrunn av radiologiske funn $(5,14)$.

Hos de fleste med idiopatisk intrakranial hypertensjon vil fremstilling av venesinus ofte avdekke en viss grad av stenose i sinus transversus (fig 2a). Patofysiologisk mekanisme og årsaksforhold ved slike stenoser er ikke tilstrekkelig belyst. Asymmetrisk kaliber av sinus transversus mellom høyre og venstre side innebærer ofte ikke noe patologisk og er vanlig hos friske, mens enkelte hevder at

Tabell 1 Hoved-og tilleggskriterier for idiopatisk intrakranial hypertensjon. Radiologiske tegn på høyt intrakranialt trykk er: 'avflating av bakre øyepol, tom sella, utvidelse av perioptisk subaraknoidalrom (væske rund opticusskjeden), stenose av sinus transversus

\section{Diagnose}

Sikker idiopatisk intrakranial hypertensjon

Sannsynlig idiopatisk intrakranial hypertensjon

Idiopatisk intrakranial hypertensjon uten papillødem

Antatt idiopatisk intrakranial hypertensjon uten papillødem
Hovedkriterier

$A+B+C+D+E$

$A+B+C+D$

$B+C+D+E$

$B+C+D+E$

\section{Tilleggskriterier}

Ingen

lngen

Abducensparese

Minst 3 radiologiske tegn på høyt intrakranialt trykk 
manglende stenosering av sinusvenene kan være en grunn til å revurdere diagnosen idiopatisk intrakranial hypertensjon $(1,14)$.

Andre MR-funn som assosieres med tilstanden er såkalt tom sella (empty sella) og forandringer relatert til $\mathrm{n}$. opticus og avflating av bakre øyepol (fig $2 \mathrm{~b}-\mathrm{d}$ ). Ingen MRfunn har kombinert høy sensitivitet og spesifisitet, og få har studert prediktiv verdi av kombinasjoner av radiologifunn (14). I en studie med barn med idiopatisk intrakranial hypertensjon fant man at kombinasjonen av tre eller flere MR-funn (sinusvenestenose ikke inkludert) hadde en sensitivitet på $45 \%$ og en spesifisitet på $95 \%$ (14). Figur $2 a-d$ viser eksempler på typiske MR-funn assosiert med idiopatisk intrakranial hypertensjon. Der det er kontraindikasjon mot MRundersøkelse er CT-undersøkelse med kontrast og CT-venografi et godt alternativ.

\section{Differensialdiagnostikk ved papillødem}

Sinusvenetrombose må alltid utelukkes radiologisk ved nyoppstått hodepine og mulig synsaffeksjon. Malign hypertensjon er en kjent årsak til bilateralt papillødem og hodepine.

Fokale forandringer i øyebunnen, for eksempel papilldruser (gulhvite kalkavleiringer, ofte beliggende på papillen) er differensialdiagnoser til «ekte» papillødem, Mer enn halvparten av pasienter med papilldruser har også hodepine (15).

Infiltrativ optikusnevropati relatert til malignitet, infeksjon eller inflammasjon kan gi papillødem. Nøyaktig somatisk status, anamnese og generelle blodprøver og eventuelt spinalvæskeundersøkelse er derfor viktig innledningsvis i utredningen.

\section{Behandling}

Grenseforhøyet åpningstrykk ved spinalpunksjon er en diagnostisk utfordring hos hodepinepasienter med mistenkt idiopatisk intrakranial hypertensjon. Selv uten definert patologisk spinalvæsketrykk kan en ødematøs øyepapill indikere at synsfunksjonen er truet og gi grunn til rask behandling. I motsatt fall kan pasienter med patologisk forhøyet spinalvæsketrykk, men normalt synsfelt og uten tegn til papillødem behandles konservativt og med bred differensialdiagnostisk tilnærming, selv om radiologiske funn indikerer høyt intrakranialt trykk.

Behandlingsmål ved ethvert tiltak er å bevare synsfunksjonen og redusere hodepinen. Pasienter med kun hodepine skal hovedsakelig behandles konservativt. For majoriteten av pasientene vil primærbehandlingen være vektreduserende tiltak og bruk av en karbonsyreanhydrasehemmer. Vektreduksjon er effektivt hos de fleste og anbefales alltid dersom det er overvekt eller opplysninger om nylig vektøkning i anamnesen (16).
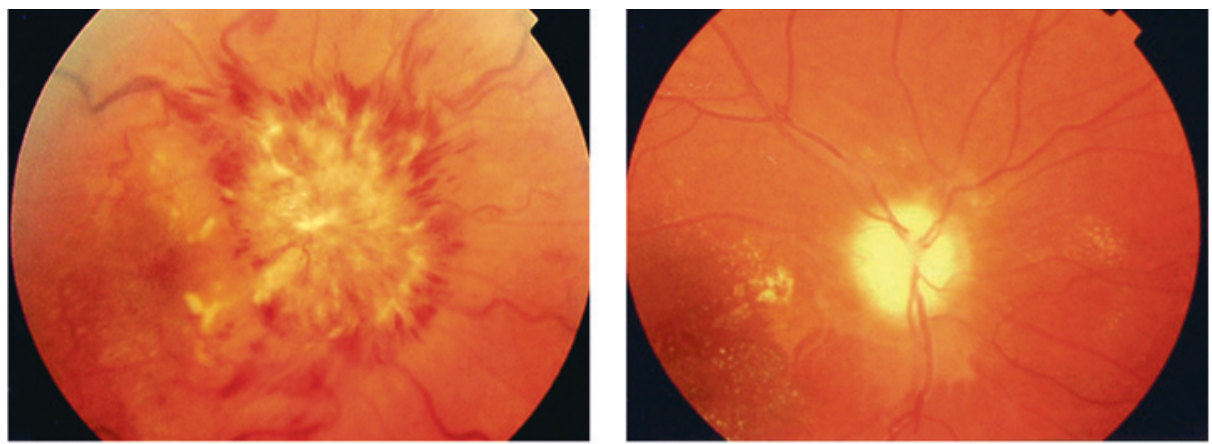

Figur 1 a) Fulminant papillødem. b) Sluttresultat: optikusatrofi
Det er vist at karbonsyreanhydrasehemmeren acetazolamid reduserer spinalvæskeproduksjonen $(17,18)$. Et begrenset antall randomiserte, kontrollerte studier har vist signifikant effekt av acetazolamid på synsfeltsutfall ved idiopatisk intrakranial hypertensjon $(9,17,18)$. Etter vår erfaring bør acetazolamid trappes opp til høyeste tolererbare dose (2 500-3 $000 \mathrm{mg} / \mathrm{d})$, men lavere

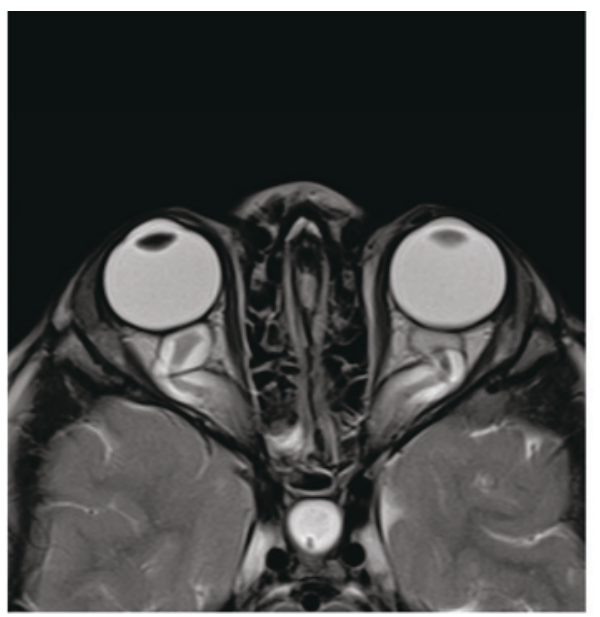

a

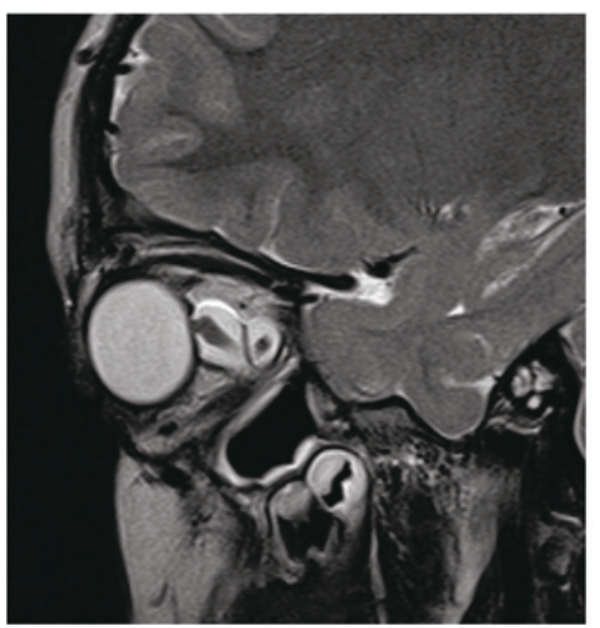

c doser (750-1 000 mg/d) kan også være effektivt. For barn doseres acetazolamid etter vekt, $15-25 \mathrm{mg} / \mathrm{kg} 3 \times$ daglig. Effekten er oftest raskt innsettende, fra noen dager til få uker etter oppstart.

Topiramat er en svak karbonsyreanhydrasehemmer med antiepileptisk og migreneforebyggende effekt, der appetittreduksjon er en vanlig bivirkning. En åpen studie

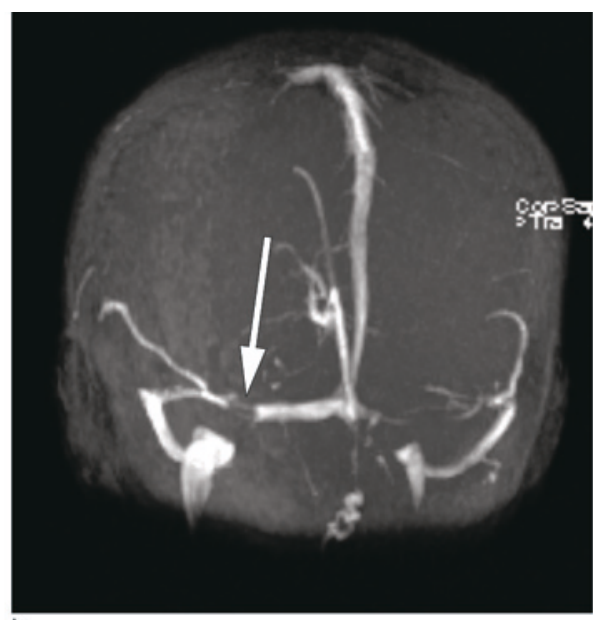

b

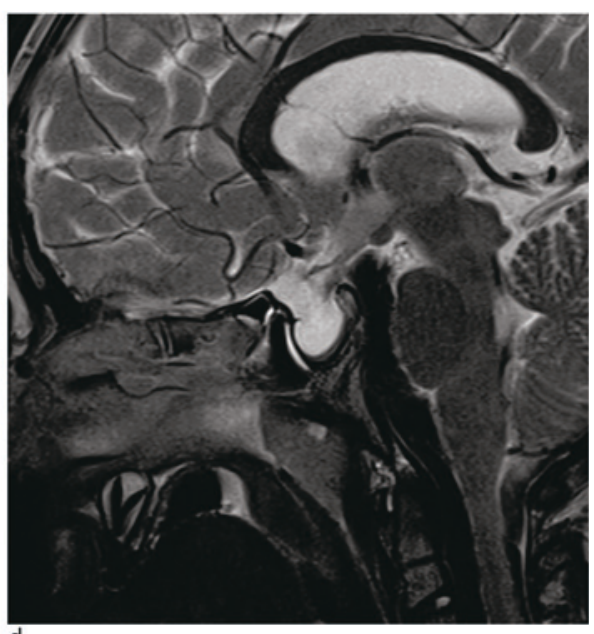

d
Figur 2 a) Utvidet subaraknoidalrom rundt n. opticus. b) Sinusvenestenose. c) Slynget n. opticus med væske rundt. d) Tom sella 
fra 2007 viste lik effekt av acetazolamid og topiramat på synsfelt og et større vekttap i topiramatgruppen, noe som kunne forklare noe av effekten (19). Behandlingseffekt av furosemid ved idiopatisk intrakranial hypertensjon er ikke dokumentert.

Medikamenter som vitamin A-preparater, tetrasykliner og veksthormoner er assosiert med idiopatisk intrakranial hypertensjon, uten at patogenesen er kjent. Individuelle vurderinger må gjøres, men vår anbefaling er at slike medikamenter bør seponeres hvis mulig.

Vanlige analgetika som paracetamol og ibuprofen har ofte effekt på hodepine ved idiopatisk intrakranial hypertensjon. Hos personer med kjent sykdom og vedvarende hodepine etter normalisering av det intrakraniale trykket og tilbakegang av papillødemet må man ha muligheten for medikamentindusert hodepine in mente.

\section{Kirurgisk behandling}

Ved fulminant forløp og økende synsfeltsutfall trass i medikamentelle tiltak kan kirurgisk intervensjon med lumboperitoneal eller ventrikuloperitoneal shunting være nødvendig for å bevare synsfunksjon. Indikasjon for shunt vurderes fortløpende ved hyppige øyelegevurderinger og i samråd med nevro$\log$ og nevrokirurg.

Kirurgi med fenestrasjon av synsnerveskjeden gjøres sjelden i Norge, og det mangler foreløpig sammenlignende studier. Endovaskulær stentbehandling ved stenose er omdiskutert og kan være forbundet med høy komplikasjonsrate $(17,18)$.

I en oversiktsartikkel fant man at bariatrisk kirurgi (fedmekirurgi) hadde effekt på symptomene ved idiopatisk intrakranial hypertensjon hos 56 av 62 pasienter. Kontrollerte studier er nødvendig for å belyse kostnad-nytte-effekten av slik kirurgi ved denne tilstanden (20).

Spinalpunksjon og tapping av spinalvæske Spinalpunksjon og tapping av spinalvæske kan gi en kortvarig bedring av hodepine og synsfunksjon. Enkelte pasienter har nytte av gjentatt tapping av spinalvæske eller anlegging av lumbal sil, og noen holder seg ved- varende asymptomatiske ved hjelp av gjentatte tappinger $(17,18)$.

Kunnskapsgrunnlaget for gjentatt spinalvæsketapping er mangelfull. Repeterende punksjoner innebærer en belastning for pasienten og er ikke risikofritt. Mange vil likevel foretrekke spinalvæsketapping over en periode dersom pasienten ved det forblir symptomfri.

\section{Oppfølging}

Pasienter med idiopatisk intrakranial hypertensjon må følges individuelt, avhengig av alvorlighetsgraden av synsutfall og hodepine. Oppfølging krever samarbeid mellom flere fagfelter og involverer fastlege, øyelege og nevrolog. Fastlege må bistå pasienten og tilpasse kontakten med spesialisthelsetjenesten ved økende symptomer.

Kontrollene bør bestå av jevnlig øyelegevurdering av visus, perimetri og fundusfotografi, i nært samarbeid med nevrolog med henblikk på videre behandling og eventuell indikasjon for henvisning til nevrokirurg.

\section{Anette Huuse Farmen (f. 1972)}

er lege i spesialisering i nevrologi og overlege. Forfatter har fylt ut ICMJE-skjemaet og oppgir ingen interessekonflikter.

\section{Geir Ringstad (f. 1972)}

er spesialist i radiologi og overlege. Forfatter har fylt ut ICMJE-skjemaet og oppgir ingen interessekonflikter.

\section{Emilia Kerty (f. 1948)}

er spesialist i øyesykdommer og i nevrologi, overlege og professor.

Forfatter har fylt ut ICMJE-skjemaet og oppgir ingen interessekonflikter.

\section{Litteratur}

1. Friedman DI, Liu GT, Digre KB. Revised diagnostic criteria for the pseudotumor cerebri syndrome in adults and children. Neurology 2013; 81: 1159-65.

2. Balcer LJ, Liu GT, Forman S et al. Idiopathic intracranial hypertension: relation of age and obesity in children. Neurology 1999; 52: 870-2.

3. Markey KA, Mollan SP, Jensen RH et al. Under- standing idiopathic intracranial hypertension: mechanisms, management, and future directions. ancet Neurol 2016: 15: 78-91.

4. Corbett JJ, Savino PJ, Thompson HS et al. Visual loss in pseudotumor cerebri. Follow-up of 57 patients from five to 41 years and a profile of 14 patients with permanent severe visual loss. Arch Neurol 1982: 39: 461-74.

5. Fisayo A, Bruce BB, Newman NJ et al. Overdiagnosis of idiopathic intracranial hypertension. Neurology 2016; 86: 341-50.

6. Dandy WE. Intracranial pressure without a brain tumor. Diagnosis and treatment. Ann Surg 1937; 106: $492-513$

7. Wall M, Falardeau J, Fletcher WA et al. Risk factors for poor visual outcome in patients with idiopathic intracranial hypertension. Neurology 2015 85: 799-805.

8. Wall M. The headache profile of idiopathic intracranial hypertension. Cephalalgia 1990; 10: $331-5$

9. Wall M, Kupersmith MJ, Kieburtz KD et al. The Idiopatic Intracranial Hypertension Treatment Trial. JAMA Neurol 2014; 71: 693-701.

10. Yri HM, Fagerlund B, Forchhammer HB et al. Cognitive function in idiopathic intracranial hypertension: a prospective case-control study. BMJ Open 2014; 4: e004376.

11. Frisén L. Swelling of the optic nerve head: a staging scheme. J Neurol Neurosurg Psychiatry 1982 45: $13-8$

12. Avery RA, Shah SS, Licht DJ et al. Reference range for cerebrospinal fluid opening pressure in children. N Engl J Med 2010; 363: 891-3.

13. Eide PK, Kerty E. Static and pulsatile intracranial pressure in idiopathic intracranial hypertension. Clin Neurol Neurosurg 2011; 113: 123-8.

14. Bidot S, Saindane AM, Peragallo JH et al. Brain Imaging in Idiopathic Intracranial Hypertension J Neuroophthalmol 2015; 35: 400-11.

15. Mustonen E, Kallanranta T. Toivakka E. Neurological findings in patients with pseudopapilloedema with and without verified optic disc drusen. Acta Neurol Scand 1983; 68: 218-30.

16. Sinclair AJ, Burdon MA, Nightingale PG et al. Low energy diet and intracranial pressure in women with idiopathic intracranial hypertension: prospec tive cohort study. BMJ 2010; 341: c2701.

17. Lueck C. Mcllwaine G. Interventions for idiopathic intracranial hypertension. Cochrane Database Syst Rev 2005; nr. 3: CD003434.

18. Biousse V, Bruce BB, Newman NJ. Update on the pathophysiology and management of idiopathic intracranial hypertension. J Neurol Neurosurg Psychiatry 2012; 83: 488-94.

19. Celebisoy N, Gökçay F, Sirin H et al. Treatment of idiopathic intracranial hypertension: topiramate vs acetazolamide, an open-label study. Acta Neurol Scand 2007: 116: 322-7.

20. Fridley J, Foroozan R, Sherman V et al. Bariatric surgery for the treatment of idiopathic intracranial hypertension. J Neurosurg 2011; 114: 34-9.

Mottatt 5.3. 2016, første revisjon innsendt 6.7 2016, godkjent 30.9. 2016. Redaktør: Tor Rosness. 